
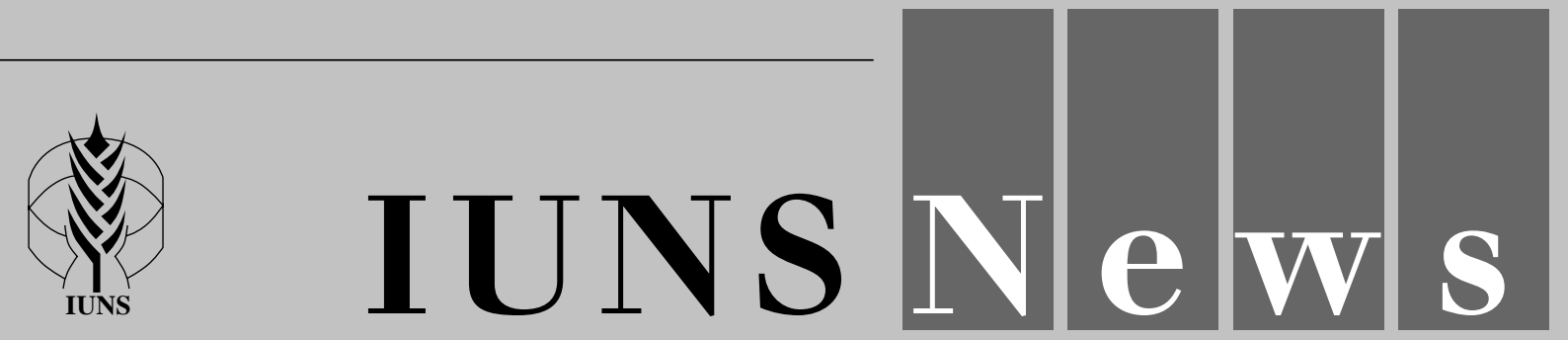

International

Union of

Nutritional Sciences

(IUNS)

\section{Council 2005-2009}

\section{Officers}

\section{President}

Ricardo Uauy Santiago de Chile

President-Elect

Ibrahim Elmadfa Vienna

Vice-President

Lindsay Allen Davis, Calif.

Secretary General

Osman Galal Los Angeles, Calif.

\section{Treasurer}

Suzanne Murphy Honolulu, Hawaii

Immediate-Past-President

Mark Wahlqvist victoria

\section{Members}

Kamala Krishnaswamy Hyderabad Anna Lartey Legon

J. Alfredo Martinez Pamplona Marja Mutanen Helsinki

Hee Young Paik Seoul

Helio Vannucchi São Paulo

\section{Mission}

The objects of the International Union of Nutritional Sciences are:

- To promote advancement in nutrition science, research and development through international cooperation at the global level

- To encourage communication and collaboration among nutrition scientists as well as to disseminate information in nutritional sciences through modern communication technology.

\section{Task Forces}

- Diet Nutrition and Long-Term Health

- Indigenous Peoples' Food Systems and Nutrition

- Nutrition in Transition

- INFOODS

- Eco-Nutrition

- Technologies and Nutrition

- Evidence Based Nutrition (EBN)

- Prevention and Control of Malnutrition

- Redefining Food Quality

\section{Contact Information}

International Union of Nutritional Sciences (IUNS)

c/o UCLA School of Public Health

Dr. Osman Galal, Secretary General

P.O. Box 951772

Los Angeles, CA 90095-1772

USA

info@iuns.org

For a list of events and adhering/affiliated bodies, please go to www.iuns.org 